\title{
Culture and leisure cluster in the post-industrial city: the case of Metaxourghio in Athens
}

\author{
V. Mavratzas \\ University of Thessaly, Greece
}

\begin{abstract}
During the last years globalisation has greatly changed the financial features and structure of post-modern cities. Urban space is subject to continuous transformations; superstructures, whose aims are to increase the competitiveness of the place and the reorganization and diffusion to a large extent, tend to make the former "compact city" disappear. The landscape of a post-industrial city is dominated by distinguishable symbolic centres (clusters) that are categorized as culture and leisure clusters, but also as enterprise clusters. They occupy central territorial units of urban space, altering the character of degraded and historical regions. The present paper looks into the case of Metaxourghio, a historical quarter in the centre of Athens, which is currently developing into a cluster of culture and popular leisure.

Key words: Metaxourghio, new urban landscapes, new urban economies, postindustrial city, cultural cluster, cluster of popular leisure.
\end{abstract}

\section{Introduction}

The post-industrial city $[1,2]$ has two main characteristics: 1 . the mixture of the way that land is used (residences, trade, services, recreation) and 2. a hierarchical multi-centric structure. It is indeed a fact that modern cities do not only have one city centre but two or more, where many different activities take place.

From the 1990s and on, along with the development of the new urban economies of the post-industrial city [3], the progressive transformation of the prevailing structure model of the way that ground is used has began in the direction of the creation of 'selective territorial concentrations' (clustering) of 
new urban economic activities. In the centre of the post-industrial city large clusters tend to be created: 1. Financial enterprises that provide high quality services plus companies or institutions of high-technology and know-how and, 2. Enterprises of cultural and recreational activities, which constitute creative islands of the new economy and shape new located pockets into the web (clusters) $[4,5]$.

The creation of clusters is promoted and supported by the city authorities through projects of reconstruction or reformation of the urban grounds and aim at the creation of symbolic urban landscape of glamour, power and growth $[6,7]$.

In the current research we will analyse the case of Metaxourghio in Athens, an emerging cultural and recreational activities cluster. The participation of the city authorities towards the promotion of the sub-centre is examined, along with the strengthening of the cohesion and the ability of the society to function in an organised way. The reasons that have led to the creation of the cluster are investigated and the ones that have discouraged its growth are presented. Finally, the possibility of participation of local residents and businesses in the planning process through the constitution of societies and committees is looked into.

\section{Metaxourghio - tactics of the state and its results to the area's growth}

Metaxourghio is placed in the north-western part of the historical centre of Athens and more particularly its boundaries are defined by Deligianni St., Pireos St., Hiera Odos St., Konstantinoupoleos St., Andromahis St., Karaiskaki Square, Aghiou Konstantinou St. and Omonias Square. It is one of the most centrally located districts of Athens and it borders the historical centre of Athens in the north, Kolonos in the east, Psirri in the west and Gazi in the south.

Metaxourghio constitutes a transitory place, a vital part of the urban web liable to territorial and social transformations. Since the mid 90s pressure concerning political choices with regard to the 'modernization' of the Greek society has intensified. Objectives and priorities have been set anew and a transition from an "old style" urban planning, accompanied by all the drawbacks of totally rational urban planning, to more emblematic and selective interventions realized by the directness offered by parallel planning and realization, having as a basic drawback the concentration on the promotion of an area's competitiveness through the promotion of its image, has been regarded.

In Metaxourghio both these two models coexist and their weaknesses are obvious. The former has been expressed through the definition of land use and the later through the application of an urban program of transformation [8]. When recording the area's character, territorially as well as socially, one notices the rapidly increasing development of uses of a broader character in comparison with the existing uses of local character.

The study conducted in 1991 for Athens district authorities has been used as the main source for the Presidential Decree 23.7 - 19.8.1998 [FEK D/616, (FEK 
is the Greek abbreviation for the official journal of the Hellenic Republic)] under the subject: 'Land uses and spatial conditions for land development in Metaxourghio'. This PD was issued when similar PDs regarding the adjacent quarters Psirri and Gazi had already been published and were in favour of the development of uses concerned with recreation in these areas. The PD concerning Metaxourghio is different from the above since it restricts - and in some cases prohibits - the uses concerning recreation, promoting primarily the use of residency. One important part of this PD, however is that in accordance with PD 84/84 it prohibits industrial activity in Metaxourghio. It is worth mentioning that in 1990 such uses were dominant in this area. Through the enforcement of this PD 59 car industry related businesses have stopped working.

Nine years after the PD has been issued, the use of ground in ground floors and floors is presented in Figures 1 and 2.

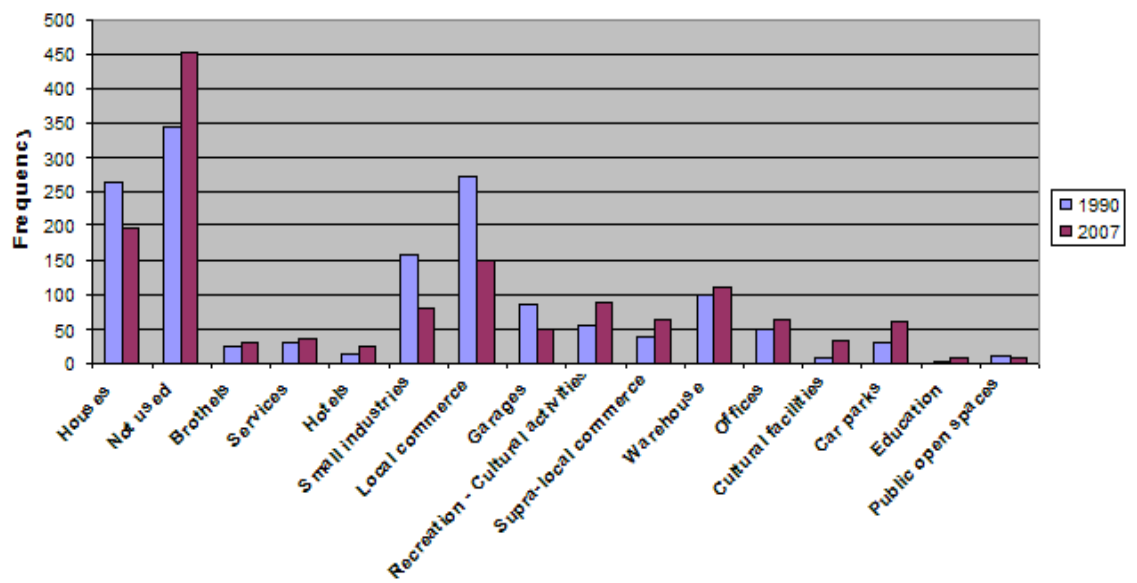

Figure 1: Uses of ground in ground floors in Metaxourghio in 1990 and in 2007.

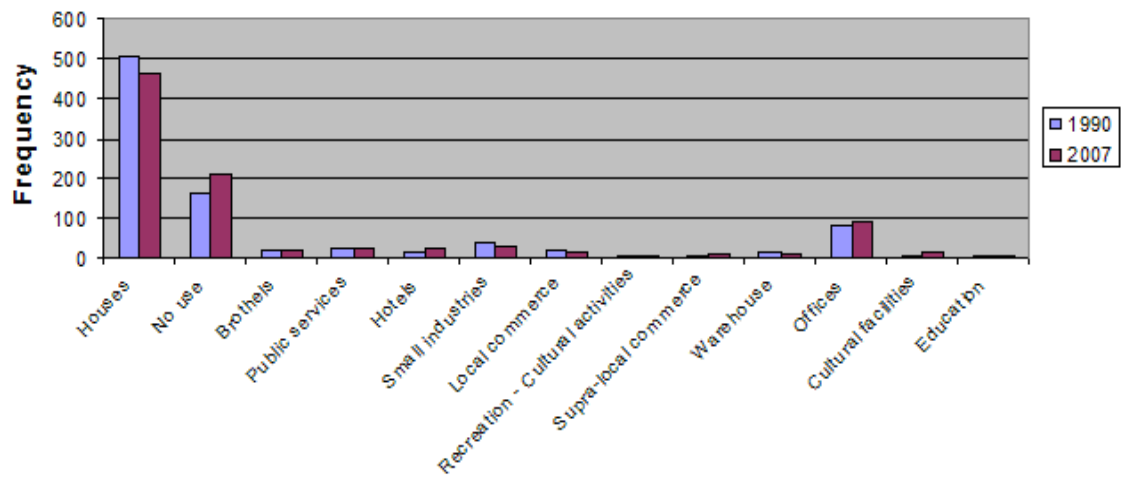

Figure 2: $\quad$ Uses of ground in floors in Metaxourghio in 1990 and in 2007. 
As it is shown in Figure 1 during the period 1990-2007 the frequency in which deserted ground floors appear has risen. At the same time, residency and small industrial activities, including garages and local retailers, has declined. More generally, this fact shows the destabilisation of a system that a decade ago was gradually moving towards stabilization.

On the other hand, the frequency in which uses of recreational aspect, restaurants and similar facilities, trade and wholesale, warehouses, offices, cultural centres and car parks appear has risen. This raise of uses such as recreation, restaurants and offices has to do with qualitative changes. In the past recreation was linked to local coffee-shops, while today it is linked to bars and night clubs. Accordingly, old small taverns have been replaced by post-modern international cuisine restaurants, which generally appeal to higher socioeconomic classes, while they do not attract the larger part of the local population. It is interesting to notice that car parks have multiplied, which reveals the broader character of new land use not restricted to locals and at the same time the installation of higher economic class residents, owning more than one luxurious car, who can afford the purchase of land and parking lots.

The results arising from Figure 2 are more or less the same. However, the use of ground in ground floors should be emphasized for two reasons: firstly, because of the great number of detached houses meant to be used as residences or offices, as well as empty building plots that were located during the research and secondly because in 1990 only the main use of the remaining floors was recorded, which has consequently affected the methodological choices of the 2007 research. A more detailed recording per floor would have resulted in interesting facts about the changes in the region, such as the transformation of industrial buildings into offices and the installation of higher economic class residents in upper floors with a view of the Acropolis.

\section{The results of the field research}

The area under research was imprinted from $28^{\text {th }}$ November to $21^{\text {st }}$ December 2007, while at the same time facts relevant to the research were gathered through Athens urban planning office and Greek statistics office. The main use of each building was imprinted, aiming basically for the imprinting of the current situation of functions in the area in order to produce a mapping basis.

The research focuses on the uses observed internationally in cultural and recreational centres, which include places of cultural expression and popular leisure, as well as other additional activities. Next, a table about the categorization of uses detected in the area under research is presented.

Next, a table presenting the number of uses that correspond to each category is shown.

The graphical representation of the table is presented below:

From Figure 3 we realize that the majority of activities in Metaxourghio concern shops $(20,17 \%)$, and other uses - such as car parks, garages, warehouses, churches $(15,05 \%)$ - and residences $(13,54 \%)$ follow. Recreation, 
Table 1: $\quad$ Categories of land use.

\begin{tabular}{|c|c|c|}
\hline & \multicolumn{2}{|c|}{ Categories of land use } \\
\hline 1 & Recreation & Cafés, bars, restaurants etc. \\
\hline 2 & Cultural activities & Theatres, galleries \\
\hline 3 & Education & Tutorial schools, dance schools, schools etc. \\
\hline 4 & Offices - workshops & $\begin{array}{l}\text { Ateliers and galleries of fine arts, sculpture, } \\
\text { painting, photography etc. } \\
\text { Decorative items, jewellery, carpets, fabrics } \\
\text { etc. } \\
\text { Drawing offices, design, art design, } \\
\text { architecture, industrial design etc. } \\
\text { Internet design, religious painting etc. }\end{array}$ \\
\hline 5 & $\begin{array}{l}\text { Shopping and recreational } \\
\text { centres }\end{array}$ & Recreational clusters \\
\hline 6 & Houses of ill-repute & Detached houses, often deserted \\
\hline 7 & Shops & Groceries, stationery, clothing etc. \\
\hline 8 & Services & Public services, banks etc. \\
\hline 9 & Hotels & Hotels \\
\hline 10 & Residency & Detached houses or blocks of flats \\
\hline 11 & Other uses & $\begin{array}{l}\text { Car parks } \\
\text { Garages } \\
\text { Warehouses } \\
\text { Churches }\end{array}$ \\
\hline 12 & Not used & $\begin{array}{l}\text { Empty building plots, deserted buildings, } \\
\text { unoccupied residences and shops }\end{array}$ \\
\hline 13 & Urban vegetation & $\begin{array}{l}\text { Public open spaces with vegetation, such as } \\
\text { squares and parks }\end{array}$ \\
\hline
\end{tabular}

Table 2: $\quad$ Number of businesses in each category of land use.

\begin{tabular}{|c|l|c|}
\hline & \multicolumn{1}{|c|}{ Use category } & Number of businesses \\
\hline 1 & Recreation & 88 \\
\hline 2 & Cultural activities & 33 \\
\hline 3 & Education & 7 \\
\hline 4 & Offices - workshops & 63 \\
\hline 5 & Shopping and recreational centres & 30 \\
\hline 6 & Houses of ill-repute & 292 \\
\hline 7 & Shops & 36 \\
\hline 8 & Services & 25 \\
\hline 9 & Hotels & 196 \\
\hline 10 & Residency & 218 \\
\hline 11 & Other uses & 452 \\
\hline 12 & Not used & 8 \\
\hline 13 & Urban vegetation & \\
\hline
\end{tabular}




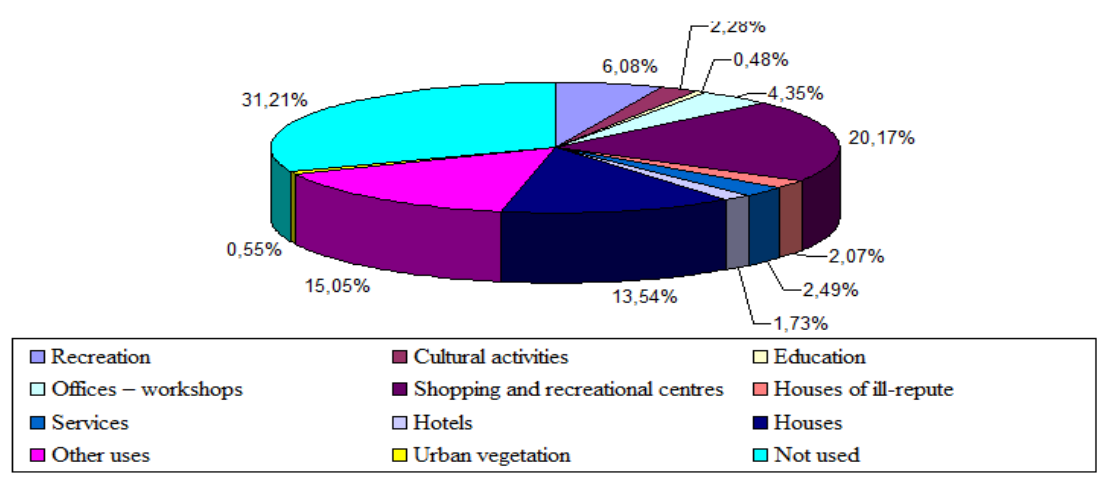

Figure 3: Land use percentages.

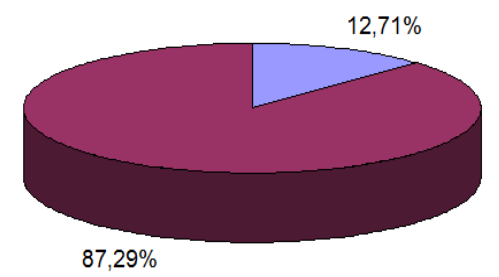

$\square$ Cluster activities

$\square$ Other activities

Figure 4: Cluster activities percentages.

offices, workshops and cultural activities directly linked to the cluster activities occupy $12,71 \%$, which verifies that the cultural and recreational centre is not fully developed. These percentages are presented in Figure 4.

What is stated above happens because the placing procedure of businesses related to the cluster has started in the last few years, while warehouses and garages have not been fully removed from the area in order for its character to change. Finally, a very important conclusion, which is drawn from the above graph, is that the percentage of deserted houses appears to be very high.

\section{Dynamic activities of growth of Metaxourghio}

\subsection{Luxurious residences complex in Metaxourghio}

During the late 90 s a major construction company constructed two separate blocks of flats in the complex situated between Milerou St., Leonidou St., Marathonos St. and Germanikou St. In the spring of 2007 this company announced an international architectural competition about the drawing of a residential and shopping complex in Metaxourghio.

This project is of great importance since it stresses the participation of big construction capital, in order to include activities relevant to residency. At the same time this heralds a string of changes in the area, regarding the new social 
character that is promoted. According to the announcement of the project contract "... the designers have to respond to the need to connect the complex to the present or future character of the area" [9] which is more or less the same with the character of Psirri or Gazi, two neighbouring quarters that could already be characterized as "refined". Within this scope the announcement of the project contract defines the profile of the resident of the complex, who will be a creative and active person, possibly an artist looking for an alternative way of living in the centre of Athens, which will be closely linked to innovation and quality.

An observation related to the importance of the project concerning the alteration of activities of major investors and the changes it can bring to this area has to do with its innovative character. The successful application of this project, which is based on the experience gained by the application of smaller projects in Psirri and Gazi, is more than probable to lead to a raise of interest of big investors in this area, as well as the promotion of similar solutions.

\subsection{Artistic events of international appeal}

From $10^{\text {th }}$ September to $18^{\text {th }}$ November 2007 the $1^{\text {st }}$ Athens Biennale took place under the title "Destroy Athens" [10]. It was designed as a broad platform of promotion of cultural production as well as a link with international cultural affairs. Its aim was to become a factor of rallying and dynamic mobilization of the local artistic society and at the same time a pole of attraction for international cultural events. More precisely, these two objectives are considered linked to each other, so Biennale has been formed since its beginning as a combination of two parallel functions: a) It acts as the organizer of a periodic exhibition of contemporary art of international appeal, which will take place every two years, b) Through the realization of AB Projects, like the internet radio 'artwave radio', the organization of minor exhibitions, events and conferences, book publications and the cooperation with other initiatives, it offers possibilities for the development of cultural production and critical thought.

At the same time, a plethora of exhibitions and interactive applications took place, which had an international appeal and added a new dynamic to the centre of Athens and to Metaxourgio in particular, which was transformed into a centre of cultural and artistic activities for more than a month [11]. If these events are resumed, the promotion of the area's cultural character will be boosted.

\section{Heterogeneity of cultural activities in Metaxourghio}

Through the research that took place we notice that in the cultural centre of Metaxourghio cultural activities like theatres, galleries etc. coexist with popular leisure activities like night clubs, bars and restaurants.

The cultural cluster of Metaxourghio is self-made and quite energetic, which gives reasons for the heterogeneous character of the developing activities. The lack of an organized strategic study about the essential development and classification of objectives has led to complication regarding the businesses' placing and activities. Because of this settlement the cluster has to be characterized as heterogeneous since cultural but heterogeneous organizations 
and businesses coexist. However, an analysis shows that the cluster activities are neither conflicting nor competitive. On the contrary, cultural activities act cooperatively and interaction has positive results.

A centre is completed through contrast, since this makes it more active. Through all these different activities, which span over different times of the day, the cluster remains active and has an effect on the surrounding area attracting visitors. Through all these different cultural and recreational spots in Metaxourghio the cluster gathers momentum in a domain that creates a new status quo in Attica urban landscape.

\section{Questionnaire research}

For the present research questionnaires that concern only businessmen of Metaxourghio whose businesses are linked to the cluster activities have been filled in from $10^{\text {th }}$ to $21^{\text {st }}$ December 2007. On the whole 38 questionnaires were handed out, out of whom 20 were filled in. Because of the small number of questionnaires it was considered best to make a qualitative and not a quantitative analysis.

Through the analysis we notice that the most important reason of business placing in Metaxourghio has to do with how centrally located the area is within the urban space. The existence of similar businesses, uniqueness and the historical tradition of the area are considered less important factors of placing. The low rate of reformation, as well as high rents, acts as a suspending factor when operation of businesses is considered.

According to the businessmen's view, the installation of more businesses like traditional workshops, bookstores and businesses related to cultural activities and recreation - would improve the area and would attract more visitors. Some argue that the traditional character of the area will be improved and preserved through the installation of traditional workshops.

Through personal interviews it became obvious that the installation of more businesses in the area, either traditional or modern, does not really affect major leisure activities centres, whose owners believe that they will be favoured in such a case. On the contrary, minor businesses and especially merchants will enter a very competitive market that will force them either to develop or give up. To sum up, the majority considers the collaboration between businesses of the same domain to be positive, as far as business and general development of the area is concerned, while it is considered important that not any negative answer was given.

As far as the owners' opinion on the benefits they will obtain through the organization of their businesses in clusters is concerned, the biggest part of them believes that they will be in a better position when it comes to negotiations with public authorities (Municipality, Ministries) concerning the area's development. The exchange of ideas and know-how along with healthy competitiveness are some of the benefits that the businesses obtain through collaborations. Organised, better and more economical marketing as well as the mobility of personnel between businesses along with the improvement of the services 
quality are not included in the benefits businessmen expect to obtain through their collaboration.

The main conclusions of the questionnaire research concerning the emerging cultural and recreational centre in Metaxourghio are:

1. Its proximity to the centre of Athens and the historical background of Metaxourghio are decisive reasons for the installation of businesses relevant to culture and recreation. As it is confirmed by theory, accessibility is an important prerequisite since an underdeveloped road network and insufficient public transports in an urban area can play a decisive role in the cluster's malfunction. At the same time the big number of listed buildings, many of which constitute architectural heritage, is an important factor in the formation of the area's character. This image of the urban space is depicted in all its constituents and renders it more accessible and attractive.

2. The businessmen's ignorance with regard to the meaning of the cluster and the benefits they can obtain through it is obvious. However, on a practical level they realize that by attracting new similar businesses the raise of competition and the resulting collaborations will contribute to the development of the area and of their businesses. In the long run, the economic growth and the attraction of visitors will lead to an improvement of the area's character and to state and municipal interventions which will not have the form of urban reforms (pedestrian walkways), but proposals of organized placing and development of the existing as well as the expected complexes and public focal points.

3. The municipal and state intervention regarding the improvement of the organization and administration of the cluster of Metaxourghio has proved to be nonexistent, since up to now nothing has been done as far as the creation and the development of the centre is concerned. However, the image that has been created in the area under research seems to be mainly the result of territorial and historical coincidence.

4. While trying to locate the problems the area faces, it was realized that these do not only limit in matters of reformation and administration, but also expand into matters of a social aspect. The existence of multicultural elements seems to be affecting businessmen who consider it one of the main reasons of degradation of the area. Despite all that, there should be a common approach as far as the area's problems are concerned and a spirit of cooperation, since the multicultural element can add benefits to the cluster development.

\section{Conclusions}

As we reported, the creation of clusters is promoted and strengthened by the institutions of cities through big works of reconstruction or reformation of urban space aiming at the creation of symbolic urban landscape of glamour, power and development. In the case of Metaxourghio, the policies chosen by the institutions were related mainly to the application of selective interventions aiming at the revival of the area. The way that the land use plan was studied reflects the weakness of comprehending the mechanisms that characterize a city and the parameters that should be taken into consideration in land planning and 
urban planning level. The proposed solutions have rather intensified than solved the problems of the area and they have contributed to the destabilisation of a system that showed to be moving towards stabilization. More generally, the selective interventions were limited to the confrontation of superficial problems and needs of the region, without giving solutions to essential matters, repeating proposals concerning general good taste and cutting into pieces the historical and cultural cohesion of the region.

If we try to compare the case of Metaxourghio with international examples of development of cultural centres [12-14], we locate a very decisive difference. In the countries where the phenomenon of clusters appears, particular emphasis is given to their planning and development through big works of reconstruction or reformation of urban space, which result from international competitions and are supported by various institutions of the cities. On the contrary, in the case of Metaxourghio the cluster resulted without any vision or planning, but through accidental incidents and historical coincidences.

Based on the above stated, in the study of developmental, land-planning and urban-planning plans, the following should be taken into consideration:

1. The protection and support of the social multiculturalism of the region, the diversity and heterogeneity of values and the way of life of various groups of residents.

2. The simultaneous strengthening of cohesion and the ability of society to function in an organized way.

3. The participation of the residents and businessmen in the process of planning through the constitution of societies and committees.

4. The essential detachment of urban planning from superficial interventions, and the involvement with issues of vitality, interconnection, extroversion, attractiveness, "brightness" and mobility of the place.

5. International experience.

6. The time frame of studies and their application.

\section{References}

[1] McNeill, D. \& While, A., The New Urban Economies. Handbook of urban studies, ed. Paddison, R., Sage Publications: London, pp. 296-308, 2001.

[2] Shaw, D.V., The Post-Industrial City. Handbook of urban studies, ed. Paddison, R., Sage Publications: London, pp. 284-296, 2001.

[3] Hutton, Th. A. (2004) ' The new economy of the Inner City', Cities, 21(2): 89-108.

[4] Gospodini, A., Portraying, classifying and understanding the emerging landscapes in the post-industrial city. Cities, 23 (5), pp. 311-330, 2006.

[5] Mommaas, H., Cultural Clusters and the Post-industrial City: Towards the Remapping of Urban Cultural Policy. Urban Studies, 3(41), pp. 507-32, 2004.

[6] Gospodini, A., European cities in competition and the new 'uses' of Urban Design. Urban Design, 7(1), pp. 59-73, 2002. 
[7] Gospodini, A., Urban design, urban space morphology, urban tourism: an emerging new paradigm concerning their relationship. European Planning Studies, 9(1), pp.925-34, 2001.

[8] Makrakis-Karachalios, C., The Area of Metaxourgio in Transition; Dynamics and Actors' Tactics. 42nd ISoCaRP Congress, pp. 8-9, 2006.

[9] Makrakis-Karachalios, C., The Area of Metaxourgio in Transition; Dynamics and Actors' Tactics. 42nd ISoCaRP Congress, pp. 8-9, 2006.

[10] Athens Biennial, www.athensbiennial.org

[11] Remap, www.remapkm.com

[12] Berg, L., Braun, E. \& Winden, W., Growth Clusters in European Metropolitan Cities, European Institute for Comparative Urban Research: Rotterdam, 2001.

[13] Berg, L., Klink, H.A. \& Langen, P., Maritieme Clustering in Nederland, Erasmus University: Rotterdam, 1997.

[14] Keeble, D. \& Wilkinson, F., Collective Learning and Knowledge Development in the Evolution of Regional Clusters of High Technology SMEs in Europe. Regional Studies, 33(4), pp. 295-303, 1999. 